\title{
GEOLOGICAL BEHAVIOUR OF ROCK MASSES IN UNDERGROUND EXCAVATIONS
}

\author{
Marinos P. V. ${ }^{1}$ \\ ${ }^{1}$ Geotechnical Engineering Department, National Technical University of Athens, 15780 Athens - Greece, \\ vmarinos@central.ntua.gr
}

\begin{abstract}
The paper deals with the engineering geological behaviour of rock masses in underground excavations. In general, the application of the well-known classification systems has the drawback of not displaying necessary information concerning the behaviour of rock masses, especially the weak ones, in tunnelling. Consequently, there are many cases in which the geological "identity" of the geomaterial is lost since it is not involved in the analysis. In that way it is possible that its special characteristics are mislaid. Within this framework, a system for assessing the failure type mechanisms of the rockmass (i.e. deformation due to overstressing, overbrakes or wedge failure, "chimney" type failure, ravelling ground) for unsupported tunnel-section is presented. These parameters, used for this system, are the structure of the rockmass, the intact rock strength and the overburden thickness. The experience gained by the recent tunnelling construction in the Greek territory, under particularly difficult geological conditions, provided excellent and numerous data for this study.
\end{abstract}

Key words: rock mass classification, tunnelling, weak rock mass, failure type

\section{Introduction}

A sound and economical design of an underground excavation is based on the compilation of a realistic geological model, the engineering geological characterization of the rock mass and the appraisal of the in situ stresses and the hydrogeological conditions. Tunnelling in rock masses requires instinct knowledge of the geomaterial since the features of mineralogical composition, lithology, structure, fracturing, tectonic disturbance, weathering, and groundwater presence, vary and change frequently with tunnel depth and makes the design a procedure with great particularities.

Tunnel design is a complex procedure and is composed of several stages. In the last decades, there has been a rapid growth on the computational analysis of tunnels. Regardless to these present calculative tools and friendly software the results must be carefully reviewed due to possible lack of precision and parameter uncertainties. Hence, a clear understanding of the rock mass tunnel behaviour followed by the proper parameter specification should be a basic concern before final tunnel design analysis.

There are no clear solutions on this approach. Nowadays, the role of the geological material in the design is improved with the progress of the investigation methods, the advancement of the geotechnical classification systems and the consequent quantification of the rock masses. All these are crucial to the tunnel design. On the other hand, the wide use of the well known classifications (GSI, $\mathrm{RMR}$, Q or others) may guide to reverse or misleading results, namely the by-pass of basic geolog- 
ical and mechanical principles, which consist the fundamental background for the geotechnical design. The use of the geotechnical classification systems, as proper as it may be done, is confined to the quantification of the rock mass without any consideration on the behaviour that the geomaterial "prefers" when excavated. The behaviour in tunnelling may differ from rock mass to rock mass, even if they have the same characterization value, under the same stress field and hydrogeological conditions. An example of two equally classificated rock masses with the GSI and RMR systems but with completely different behaviour after their excavation, is shown in figure 1 .

What is highlighted in this paper is that the classification "numbers" must be also supported, in an engineering friendly way, by the engineering geological behaviour, namely the type and the mechanism of failure that "fits" best to the rock mass under consideration. Otherwise, the geological identity of the geomaterial is lost, while any in situ particularities which can be crucial to the tunnel instability may be disregarded.

Rock mass behaviour appraisal in tunnelling and its connection to the design has been the subject of significant research interest. Goricki et al. (2004), Schubert (2004), Poschl and Kleberger (2004) and Potsch et al. (2004) study the rock mass behaviour from the design and construction experience of the Alpine tunnels and Palmstrom and Stille (2007) of other tunnels.

In this context, a database named "Tunnel Information and Analysis System" (TIAS), was designed and created (Marinos et al., 2006) for Greek tunnels. A huge number of geological, engineering geological and geotechnical data from the site investigation, design and the construction of 62 tunnels of Egnatia Highway in Northern Greece were considered. The data from this information, together with relevant field work, were processed and evaluated by numerous correlations. This work resulted to a classification and a tunnel behaviour system is proposed. The results of this research intend to assist to the selection of the appropriate design parameters and the conceptual choice of the support measures.

\section{Engineering Geological Behaviour in Tunnelling}

\subsection{General}

Failures or instabilities are certainly an undesirable phenomenon to tunnel construction. Nevertheless, they express the most accurate "method" to confirm or re-evaluate the geotechnical model and thus use the appropriate design tools. The term instability mechanism-behaviour as referred here involves all the mechanisms that endanger the tunnel section either when the rock mass has not been yet supported after its excavation or temporarily supported behaving together with the support shell. In this paper, the reaction of the rock mass immediately after its underground excavation and before the support implementation is examined. Thus, the engineering geological characteristics - keys to the tunnel stability are of great importance.

\subsection{Design methodology}

A design methodology for this approach is proposed by Goricki et al. (2004) and Schubert (2004), a section of which is studied here. The first step of this methodology involves the definition of rock mass types, the second the evaluation of rock mass tunnel behaviour, the third step suggests the setting of the tunnel excavation-support system based on the previous behaviour with the inclusion of the geotechnical parameters, the fourth the detection of unified characteristics-sections of equal support requirements along the tunnel and final the fifth step the determination of the excavation and support categories qualified to cost and time terms (organization of the tender documents). This paper focuses on the second and third step. 


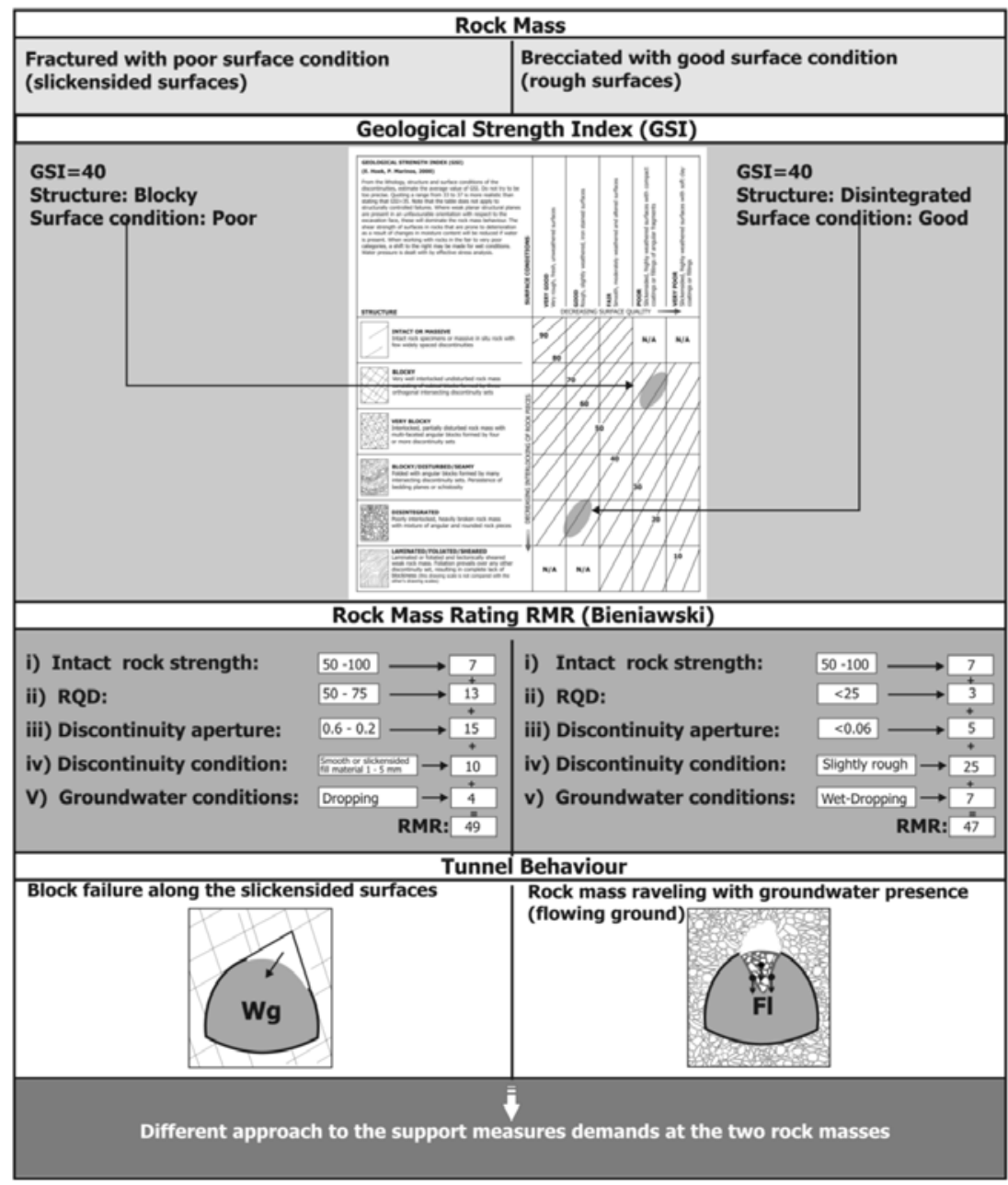

Fig. 1: Example of two equally rated rock masses with the GSI and RMR system but with completely different behaviour in tunnelling and supporting measures.

The rock mass behaviour, in a non urban environment, from the excavation of 62 tunnels in northern Greece, was examined for the purpose of this research.

\subsection{Tunnel Behaviour Types}

A tunnel behaviour assessment in order to assist to the design parameter selection and the support elements selection is presented hereafter. The behaviour type must be precise and solid. This can be achieved initially by the recognition of the general failure category, referred mainly as gravity and stress controlled and then by a more specific inspection in each category. Normally, there are cases when both general categories may be applied. Tunnel behaviour types are presented and briefly described in figure 2. It should be noted that deformation problems are estimated by the ratio of the uniaxial rock mass strength to insitu stresses, $\sigma_{\mathrm{cm}} / \mathrm{p}_{\mathrm{o}}$ (Hoek and Marinos, 2000). 


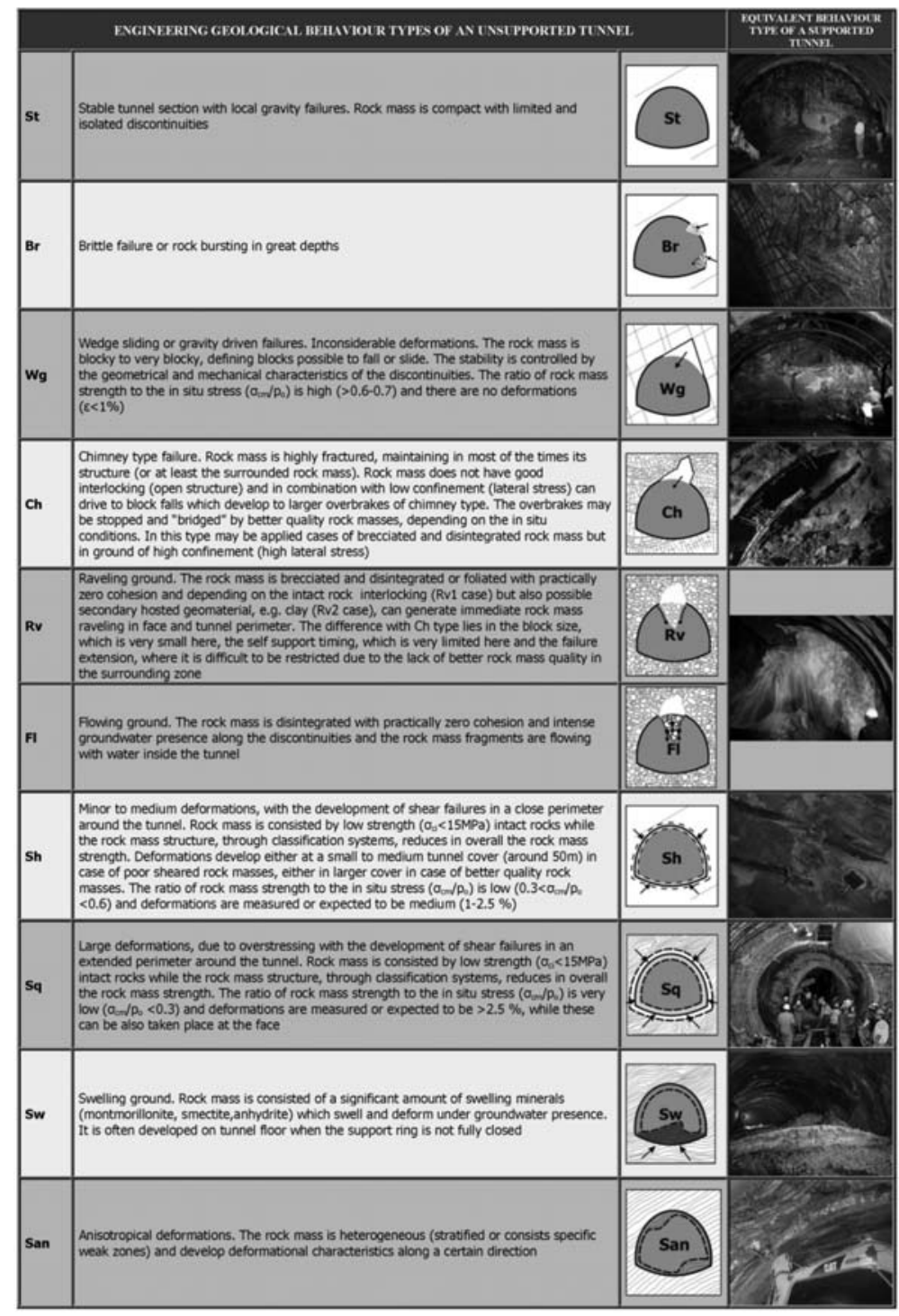

Fig. 2: Brief description and schematic presentation of the tunnel behaviour types (based on data from Potsch et. al., 2004 and from the author)

\section{Tunnel Behaviour System}

\subsection{Methodology}

The assessment of the engineering geological behaviour of the rock mass was done with a certain method-philosophy. The first step involves the understanding of the possible tunnel failures-behaviour, as far the mechanism is concerned. The next step was to define all the possible rock mass types for several formations which were identified by specific engineering geological characteristics affecting their behaviour. These types where recognized along the 62 tunnels which were investigated, together with their design parameters. The following stage involved the grouping of the support cat- 
egories for a number of rock mass models and a variety of insitu conditions. At the same time, a comparison of the rock mass behaviour after its excavation was done, in order to compare it with the design. In the next step, the effort was focused on handling the construction records. The data were justified by field work and in situ inspections and the behaviour was classificated for every rock mass type. Finally, the temporary support measures philosophy and principles for a certain behaviour type was assessed.

\subsection{Rock mass behaviour assessment}

The demand for classificated geological information, directly linked to the design and tunnel support measures to be applied, guided to a system for the assessment of the failure type mechanisms and behaviour of the rock mass for unsupported tunnel-section, based on the structure of the rock mass, the intact rock strength and the thickness of the overburden.

The suggested system, called Tunnel Behaviour Chart (TBC), is shown in figure 3. The scope of this diagram is to provide the logic and failure mechanism of several rock mass types often met in nature. It is noted that in the chart there are no quantified limits-ranges of the uniaxial compressive strength of the intact rock $\left(\sigma_{\mathrm{ci}}\right)$ and the overburden thickness $(\mathrm{H})$, but only qualitative of high and low values. However, some general quantified limits for $\sigma_{\mathrm{ci}}$ and $\mathrm{H}$ for each GSI structure column are presented in table 1 . These values although, based on reasonable trends, should only be considered as purely indicative.

The data of this assessment were based on the excavation of tunnels with the conventional method with top heading and bench in a non-urban environment with an overburden, less than $600 \mathrm{~m}$. The philosophy of the Tunnel Behaviour chart becomes more comprehensible if we acknowledge the following:

- The rock mass structure is a basic parameter to estimate its immediate response in underground excavation. The pattern of structures of the GSI system was selected.

- Overburden thickness $\mathrm{H}$ is an other principle parameter to access the behaviour type, since it is in conjunction to the insitu stresses and the general confinement conditions. The behaviour types that were examined are referred to tunnel construction under a cover of $30 \mathrm{~m}$ to $300 \mathrm{~m}$ (a case around $600 \mathrm{~m}$ was also included). For the gravity driven failures, tunnel depth can determine the extent or restrain of a failure, since the degree of interlocking between the rock blocks changes and the confinement pressure is different. For example, a ground may ravel (Rv) close to the ground surface but under higher cover a chimney type $(\mathrm{Ch})$ failure may be observed. As far as the stress controlled behaviour is concerned, overburden thickness $\mathrm{H}$ defines when shear failures and deformations are generated.

- Intact rock strength $\sigma_{\mathrm{ci}}$ values that were involved in the design of those tunnels, ranged between 5 to $40 \mathrm{Mpa}$. The selected extreme values that nominate the rock mass behaviour are based in two criteria: i) the value when shear failures and deformations initiate and ii) the value which accords best with the present deformational characteristics of the rock mass structure (e.g. fractured, brecciated, sheared).

The surface condition of the discontinuities, the second composite of GSI system, mainly affects the intensity of the failure phenomenon and is not accounted to the behaviour type definition. Only few are the cases where surface quality can accommodate a behaviour type. For example, high clay presence along the discontinuities or as a zone in the rock mass may shift the gravity driven behaviour types to the vertical axis of the chart (e.g. from Wg [9] to Ch [13]). Groundwater presence does not affect the behaviour type but affects the factor of safety. However, in some cases, like in "Disintegrated" rock mass, the groundwater presence may "shift" from a Chimney (Ch) or Raveling (Rv) behaviour type to Flowing ground $(\mathrm{Fl})$ type. 

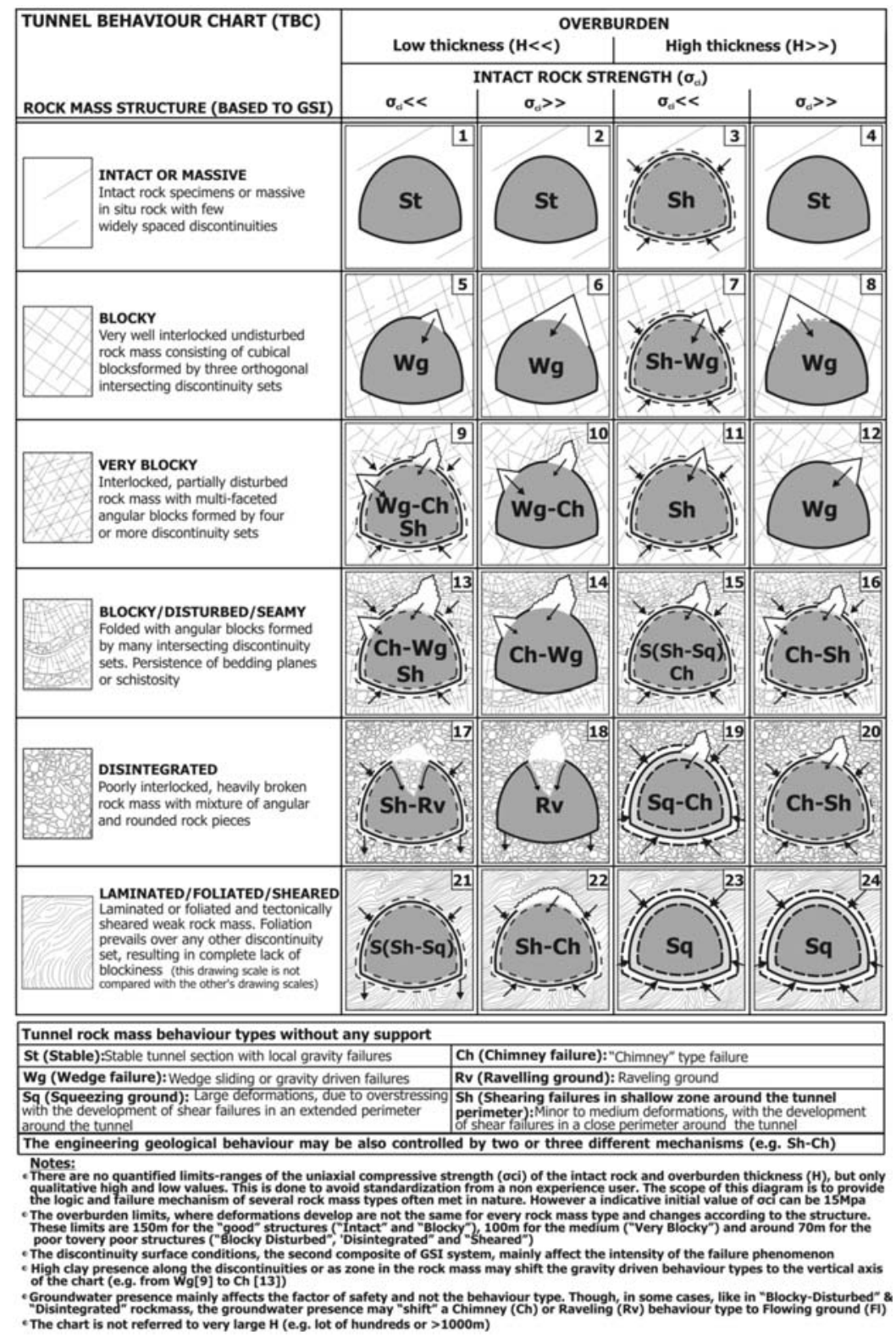

Fig. 3: Tunnel Behaviour Chart (TBC): A system for rock mass behaviour assessment.

Stress controlled failures: The development of remarkable deformations around a non-urban tunnel is characterized by a ratio of $\sigma_{\mathrm{cm}} / \mathrm{p}_{\mathrm{o}}<0.6-0.7$ (Hoek and Marinos, 2001). In particular, when $\sigma_{\mathrm{cm}} / \mathrm{p}_{\mathrm{o}}$ is among 0.3 and 0.7 , shear failures can propagate in a shallow zone around the tunnel perimeter (Sh behaviour). Such cases concern rock masses with poor to very poor structures and low intact rock strength $(<10-15 \mathrm{Mpa})$ under medium overburden or with good structures and low intact rock strength under high cover. Squeezing conditions (behaviour $\mathrm{Sq}$ ) with severe tunnel deformations may develop when $\sigma_{\mathrm{cm}} / \mathrm{p}_{\mathrm{o}}<0.3$. 
Table 1. General indicative quantified ranges for oci and overburden thickness (H) and GSI values for every tunnel behaviour type (1-24) from the Tunnel Behaviour Chart of figure 3.

\begin{tabular}{|c|c|c|c|c|}
\hline TBC Case & GSI value range & GSI Structure & $\sigma c i(M P a)$ & $\begin{array}{c}\text { Overburden thickness } \\
H(m) \text { limit }\end{array}$ \\
\hline 1,3 & $70-80$ & \multirow{2}{*}{ Intact } & $<15$ & \multirow{2}{*}{150} \\
\hline 2,4 & $70-90$ & & $>15$ & \\
\hline 5 & $50-60$ & \multirow{4}{*}{ Blocky } & $10-15$ & $20-150$ \\
\hline 6 & $50-80$ & & $>15$ & $<150$ \\
\hline 7 & $50-60$ & & $<15$ & $>150$ \\
\hline 8 & $50-80$ & & $>15$ & $>150$ \\
\hline 9,11 & $35-55$ & \multirow{2}{*}{ Very Blocky } & $10-15$ & \multirow{2}{*}{100} \\
\hline $10-12$ & $40-60$ & & $>15$ & \\
\hline 13,15 & $25-45$ & \multirow{2}{*}{ Blocky - Disturbed/Seamy } & $<15$ & \multirow{2}{*}{70} \\
\hline 14,16 & $30-50$ & & $>15$ & \\
\hline $17-19$ & $15-35$ & \multirow{2}{*}{ Disintegrated } & $<15$ & \multirow{2}{*}{70} \\
\hline $18-20$ & $35-45$ & & $>15$ & \\
\hline 21,23 & $15-25$ & Disintegrated & $<10$ & \multirow{2}{*}{70} \\
\hline 22,24 & $15-35$ & Laminated/Foliated/Sheared & $>10$ & \\
\hline
\end{tabular}

Gravity controlled failures: Gravity driven failures can take place when a rock mass is fractured in planes and is formed by blocks. When these blocks are revealed after the excavation they may fall or slide, according to the tunnel geometry and the shear strength characteristics of the discontinuity planes. Chimney $(\mathrm{Ch})$ and raveling $(\mathrm{Rv})$ types can take place in rock masses with low interlocking of blocks. The rock mass cannot "bridge" immediately after the fall and the overbreak may be irregular and significant. Volume and frequency of these behaviour types depend on the structure of the rock mass ("Blocky-Disturbed" and "Disintegrated"), its relaxation ("open structure") and the tunnel depth, since it will improve the rock mass quality and the confinement pressure which may tighten the structure of the rock blocks.

\section{Tunnel support measures - Design philosophy}

The design of the temporary support categories consists of two stages: the selection of the proper support elements and their analysis. The general concept and the selection of the elements lie on the uncertainty of the engineering geological behaviour of the rock mass. This procedure is very important, since there are cases where a specific behaviour cannot still be accurately. That is why the decision is frequently based on the experience and the geotechnical appreciation and less on analytical solutions.

Thus, in conjunction with the tunnel behaviour system, presented in the previous paragraph, this study concluded also to a step-by step procedure towards the design. This approach initiates after the definition of the rock mass types along the tunnel and the evaluation of the geological and insitu conditions. The rock characteristic - "keys", which dictates the stability or instability of the tunnel, are then assessed. The behaviour of the rock mass after its excavation in an unsupported section is then investigated and the design philosophy is defined. After the identification of the failure mechanism, the suitable design parameters can be selected. Finally, the tunnel support philosophy and the re- 


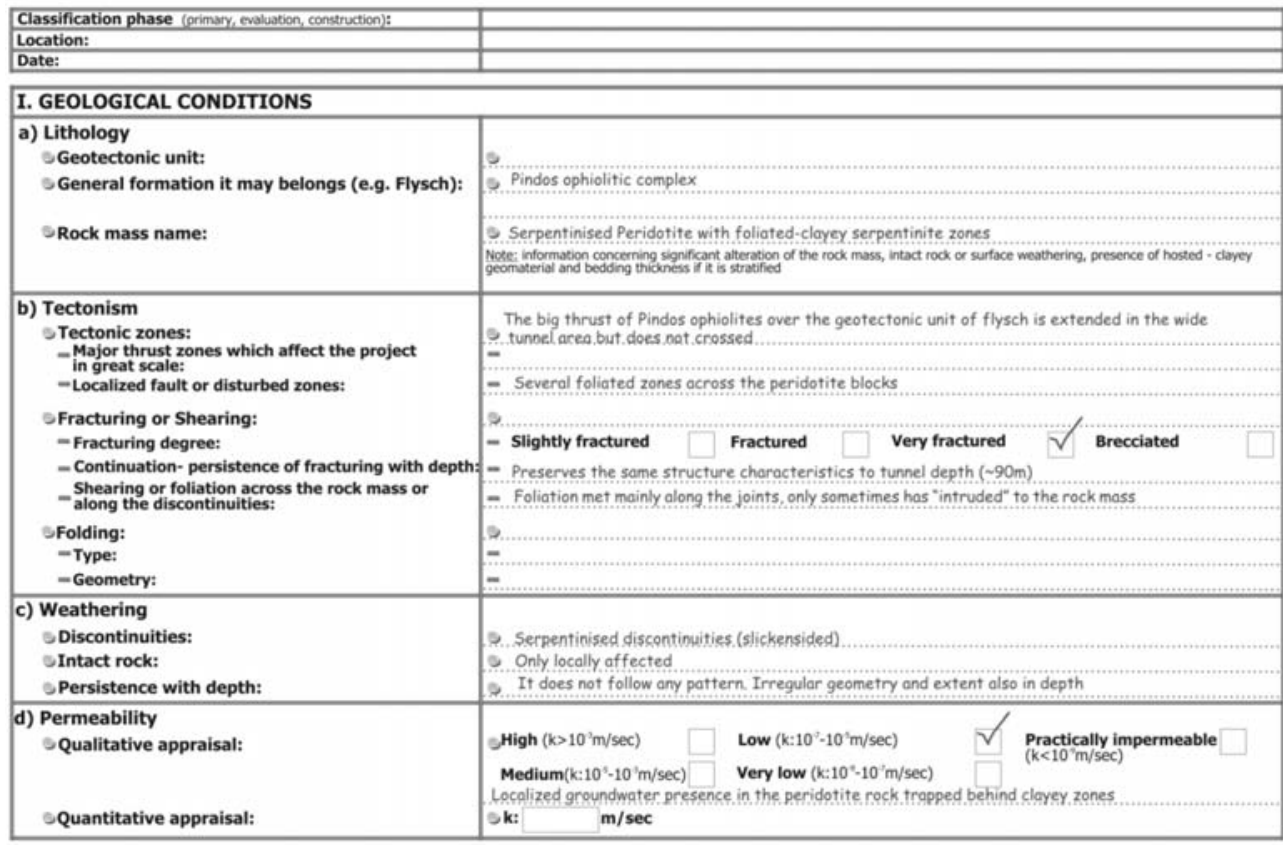

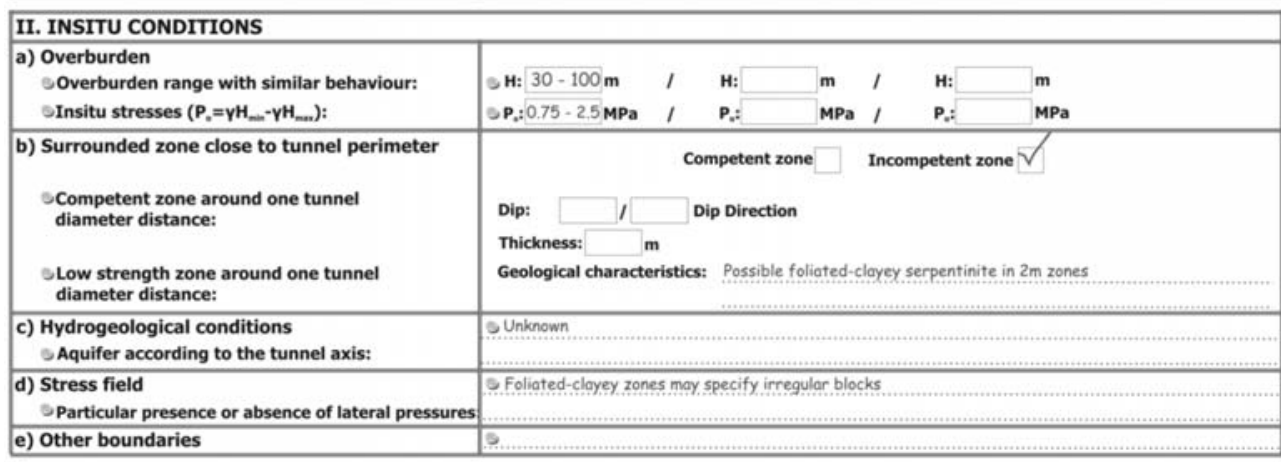

\section{CHARACTERISTIC "KEYS" FOR TUNNEL STABILITY OR INSTABILITY}

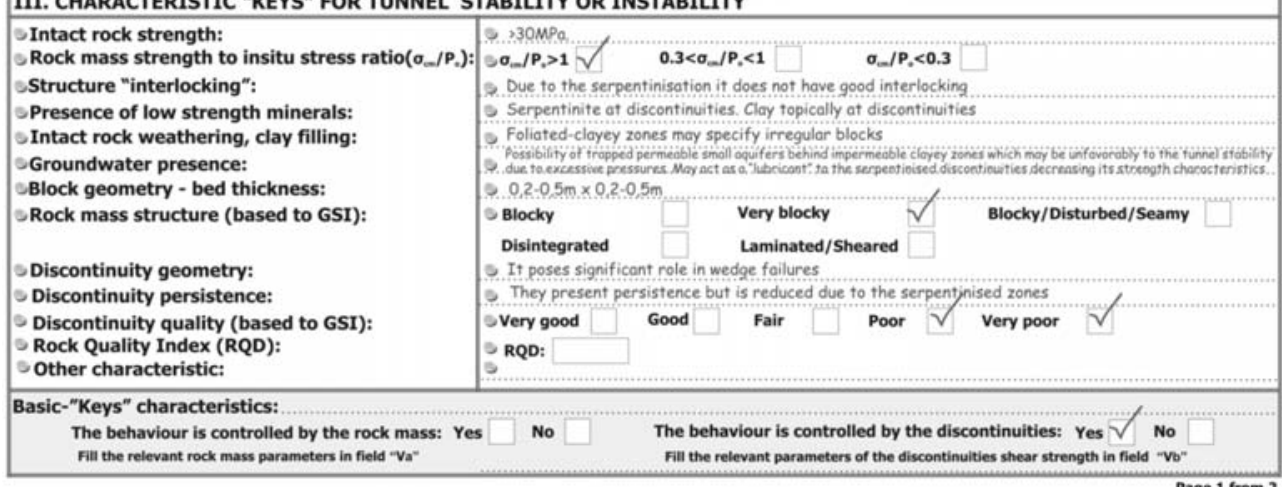

Fig. 4: Rock mass characterization method in tunnelling towards the design (Sheet 1/2). 
ENGINEERING GEOLOGICAL CHARACTERIZATION FOR TUNNELING (2/2)

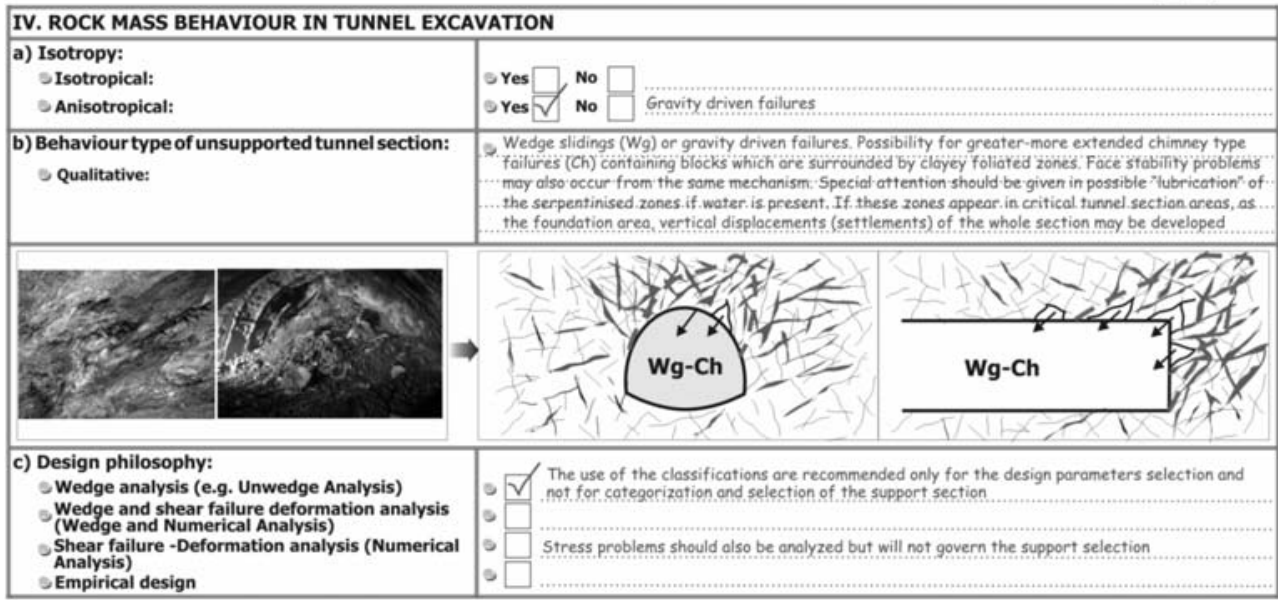

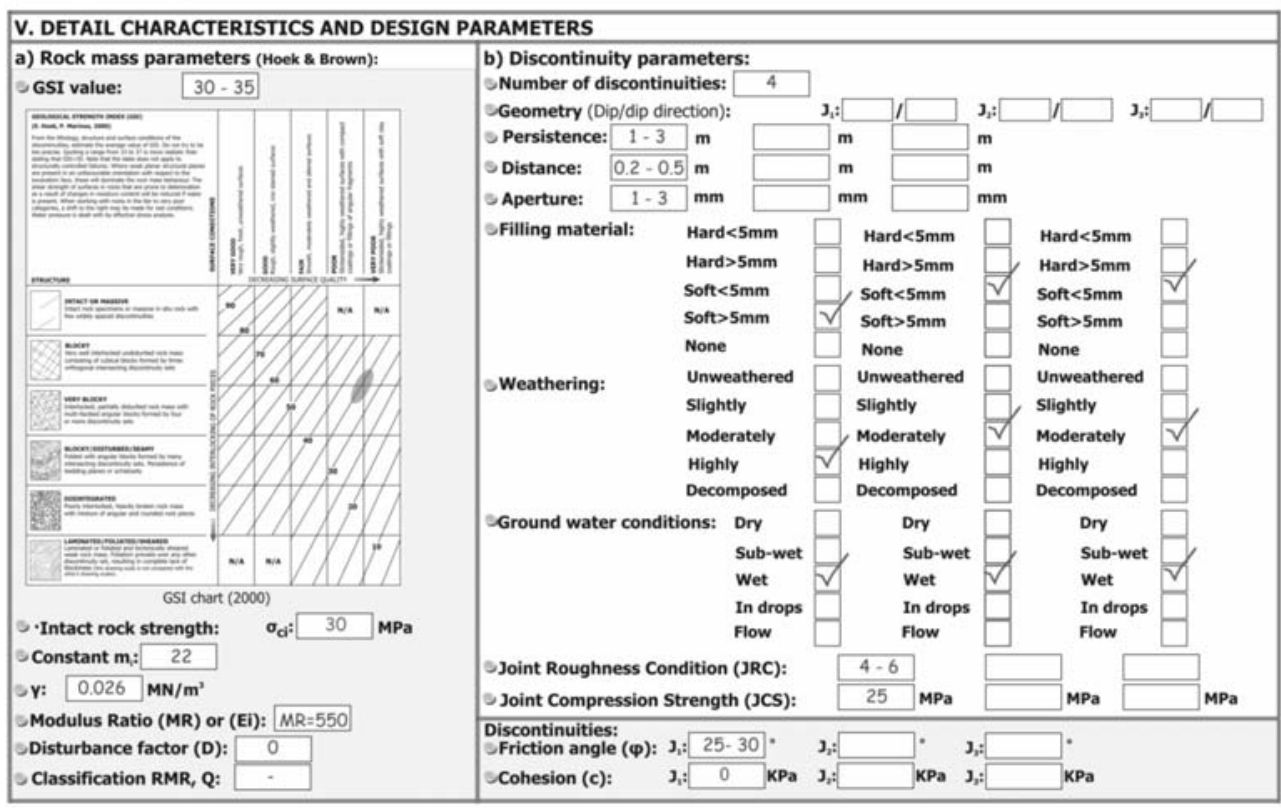

\begin{tabular}{|c|c|}
\hline \multicolumn{2}{|l|}{ VI. TUNNEL SUPPORT PHILOSOPHY } \\
\hline $\begin{array}{l}\text { QQualitative: } \\
\text {-Excavation phases: }\end{array}$ & - Two phases (Top Heading and Bench). \\
\hline $\begin{array}{l}\text {-Excavation step: } \\
\text {-Shotcrete bolts: }\end{array}$ & 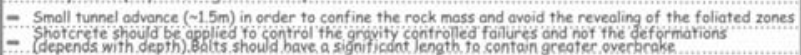 \\
\hline $\begin{array}{l}\text {-Steel sets: } \\
\text { - Not heavy face support (e.g. spiles): }\end{array}$ & $\begin{array}{l}\text { - Should be closely implemented (1-1.5m) to confine some blocks of ten marked by the weak cloyey zones } \\
\text { - It may be required to apply spiles and foce buttress in case of continuous oppearance of the clayey zones }\end{array}$ \\
\hline $\begin{array}{l}\text {-Face support } \\
\text { (e.g. fibreglass, forepolling, invert): } \\
\text {-Water drainage: } \\
\text {-Other (e.g. grouting): }\end{array}$ & 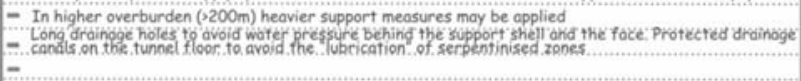 \\
\hline
\end{tabular}

\section{REMAINING RISK}

OPossible rock strength reduction due to "lubrication" by water circulation when the trenches along the funnel are poorly constructed. In this cose significant verticol convergence due to the settiement of the support shell moy developed

Fig. 5. Rock mass characterization method in tunnelling towards the design (Sheet 2/2) 
maining risk are reported. This method of rock mass characterization in tunnelling is presented in two sheets with a given example in figure 4 and 5 .

\section{Conclusions}

The use of rock mass classification systems and the resulting quantitative characterization of rock masses cannot directly correspond to their behaviour in underground excavations. Great care should be given to the assessment and sound understanding of the engineering geological behaviour types, prior to tunnel design and analysis. That is to identify the possible failure modes and nature of problems which is expected for the particular rock mass type. In that order, the selection of the tunnel support elements and characteristics together with the evaluation of the geotechnical properties can be soundly assessed from the beginning. Hence a more realistic design along the tunnel can be performed.

A methodology where the rock mass behaviour integrates to the tunnel design procedure is suggested. For this methodology, the basic step is to identify the "key" engineering geological characteristics, which control instability potential of the rock mass. Towards this direction a system for the tunnel behaviour assessment is presented based on the rock mass structure, the intact rock strength and the overburden thickness.

\section{Acknowledgments}

The author acknowledges the support and encouragement of G. Tsiambaos, Assistant Professor of the Geotechnical department of NTUA, which supervised this research. He would like to thank Egnatia Odos S.A. for its support and the assignment of the relevant research program. Special thanks should be offered to the geologist D. Papouli for her assistant to the preparation of the figures.

\section{References}

Goricki, W., Schubert, G., Riedmueller, G., 2004. New Developments for the design and construction of tunnels in complex rock masses. International Journal of Rock Mechanics and Mining Sciences, 41(3), CD-ROM.

Hoek, E., Marinos, P., 2000. Predicting tunnel squeezing in weak heterogeneous masses. Tunnels and Tunnelling International, Part 1-November Issue 2000, pp. 45-51; Part 2-December 2000, pp. 34-36.

Marinos, V., Korkaris, K., Prountzopoulos, G., Romosiou A, Fortsakis, P., Mirmiris, K., Petroutsatou, K., Koumoutsakos, D., Kiamos, K., Lazaridou, S., Pitsas, G., Rigopoulou, M., Marinos, P., Lampropoulos, S., 2006. The construction of a geotechnical database for the Egnatia Highway S.A. Proceedings of the $5^{\text {th }}$ Hellenic Geotechnical, Xanthi 2006, 3, pp. 525-531. (in Greek).

Marinos P. V. (2007). "Geotechnical classification and engineering geological behaviour of weak and complex rock masses in tunneling", Doctoral thesis, School of Civil Engineering, Geotechnical Engineering Department, National Technical University of Athens (NTUA), Athens, July (in greek).

Palmstrom, A., Stille, H., 2007. Ground behaviour and rock engineering tools for underground excavations. Tunnelling and Underground Space Technology, 27, pp. 363-376.

Poschl, I., Kleberger, J., 2004. Geotechnical risks in rock mass characterisation - Part 1. Tunnels and Tunnelling International, May issue, pp. 37-39. Part 2., October issue, pp. 36-38.

Potsch, M., Schubert, W., Goricki, A., Steidl, A., 2004. Determination of Rock Mass Behaviour Types a Case Study. EUROCK 2004 and 53th Geomechanics Colloquium, Schubert ed., VGE publ.

Schubert, W., 2004. Basics and Application of the Austrian Guideline for the Geomechanical Design of Underground Structures. EUROCK 2004 and 53th Geomechanics Colloquium, Schubert ed., VGE publ. 